\title{
ANALISIS KASUS KEMISKINAN DI PROVINSI KALIMANTAN TENGAH DENGAN PENDEKATAN PRINCIPAL COMPONENT ANALYSIS
}

\author{
Annisa Halida ${ }^{1}$, Nadya Farah Pradita ${ }^{2}$, Yuana Sukmawaty ${ }^{3}$ \\ Program Studi Statistika, Fakultas MIPA, Universitas Lambung Mangkurat \\ annisahalidaaa@gmail.com,farahpradita93@gmail.com,yuana_s@ulm.ac.id
}

\begin{abstract}
According to a report by the Central Statistics Agency, the percentage of poor people in urban areas in September 2019 was 6.89\%. Meanwhile, the percentage of poor people in rural areas in September 2019 was $13.10 \%$. The data above is only a national percentage, there are still many provinces that have a poverty percentage above the national percentage, especially in Central Kalimantan Province. There are many factors that influence poverty, including education, employment status, working sector, and per capita income. This paper focuses on a study to determine the factors that have the greatest influence on poverty in Central Kalimantan Province in 2019. The results of this study simplify the poverty factor into 2 (two) factors, namely the first factor consisting of variables of education, work status, and sector. work. Meanwhile, the second factor consists of the variable per capita income for food. In addition, the greatest eigen value was obtained in the education variable of 465.67, which indicates that the education variable has the greatest influence on poverty in Central Kalimantan Province in 2019.
\end{abstract}

Keywords: PCA, factors, and poverty

\begin{abstract}
ABSTRAK
Menurut laporan Badan Pusat Statistik, presentase penduduk miskin di daerah perkotaan pada September 2019 sebesar 6,89\%. Sementara presentase penduduk miskin di pedesaan pada September 2019 sebesar 13,10\%. Data di atas hanyalah presentase nasional, masih ada banyak provinsi yang memiliki presentase kemiskinan di atas presentase nasional, khususnya di Provinsi Kalimantan Tengah. Ada banyak faktor yang mempengaruhi kemiskinan, diantaranya pendidikan, status bekerja, sektor

\footnotetext{
${ }^{1}$ Mahasiswa Program Studi Statistika Fakultas MIPA Universitas Lambung Mangkurat Angkatan 2017.

${ }^{2}$ Mahasiswa Program Studi Statistika Fakultas MIPA Universitas Lambung Mangkurat Angkatan 2017.

${ }^{3}$ Dosen Program Studi Statistika Fakultas MIPA Universitas Lambung Mangkurat.
} 
bekerja, dan pendapatan perkapita. Paper ini berfokus pada kajian untuk mengetahui faktor yang memiliki pengaruh terbesar dalam kemiskinan di Provinsi Kalimantan Tengah pada tahun 2019. Hasil dari kajian ini menyederhanakan faktor kemiskinan menjadi 2 (dua) faktor, yakni faktor pertama yang terdiri dari variabel pendidikan, status bekerja, dan sektor bekerja. Sedangkan, faktor kedua terdiri dari variabel pendapatan perkapita untuk makanan. Selain itu, didapatkan eigen value terbesar pada variabel pendidikan sebesar 465.67 yang menunjukkan bahwa variabel pendidikan mempunyai pengaruh terbesar dalam kemiskinan di Provinsi Kalimantan Tengah pada tahun 2019.

Kata Kunci: PCA, faktor, dan kemiskinan.

\section{Pendahuluan}

Pembangunan suatu negara adalah hal yang paling utama dilakukan untuk mewujudkan kondisi yang lebih baik dimasa depan. Karena itu, pembangunan merupakan proses yang selalu meningkat dari hari ke hari dan akan berlangsung secara terus-menerus. Salah satu indikator keberhasilan. Pembangunan suatu negara adalah meningkatnya pertumbuhan ekonomi, diharapkan dengan meningkatnya pertumbuhan ekonomi yang tinggi mampu mengurangi pengangguran ataupun kemiskinan yang. ${ }^{4}$ Selain itu, membangun keberdayaan masyarakat agar mampu melepaskan diri dari perangkap kemiskinan dan keterbelakangan.

Kemiskinan sendiri adalah salah satu persoalan global. Parahnya masalah ini banyak terjadi di negara -negara berkembang seperti Indonesia. Presentase penduduk miskin pada Maret 2019 sebesar 9,41\% menurun 0,25\% terhadap september 2019 dan menurun 0,41\% terhadap Maret 2019. Tapi hal ini, dirasa masih kurang efektif dalam menangani masalah kemiskinan untuk pembangunan ekonomi. Pada laporan Badan Pusat Statistik, presentase penduduk miskin di daerah perkotaan pada September 2019 sebesar 6,89\% turun menjadi 6,69\% pada maret 2019. Sementara presentase penduduk miskin di pedesaan pada September 2019 sebesar 13,10\% turun menjadi 12,85\% pada Maret 2019. Data diatas hanyalah presentase nasional, masih ada banyak provinsi yang memiliki presentase kemiskinan di atas presentase nasional. Khususnya di provinsi Kalimantan Tengah. ${ }^{5}$

Ada banyak faktor-faktor yang membuat kebijakan pemerintah dalam menanggulangi kemiskinan belum bisa teratasi dari segi pendidikan ada pendidikan yang ditamatkan. Dari segi ketenagakerjaan ada bekerja, bekerja disektor informal, bekerja disektor formal, bekerja disektor pertanian, bukan pertanian, dan tidak bekerja. Dari segi pengeluaran perkapita untuk makanan ada pengeluaran perkapita dan presentase pengeluaran perkapita untuk makan. Untuk mengetahui faktor mana saja yang membuat persoalan kemiskinan ini belum terpecahkan, maka dari itu penulis ingin meneliti menggunakan aplikasi Principal Component Analysis dengan mereduksi faktor - faktor yang mempengaruhi.

\section{Tinjauan Pustaka}

\subsection{Analisis Multivariat}

${ }^{4}$.Rustam, Mochtar. 2010. Sinopsis Obstetri Fisiologi Patologi 3rd ed. Jakarta: EGC.

${ }^{5}$ Badan Pusat Statistik. 2019. Data dan Informasi Kemiskinan Kabupaten/Kota. 
Analisis Multivariat adalah analisis terhadap banyak variabel yang merupakan pengembangan dari analisis univariate dan bivariate. Analisis multivariat memiliki lebih dari dua variabel. Misal data dari n pengamatan pada p variabel, sehingga dapat disusun matriks dengan $\mathrm{n}$ baris dan $\mathrm{p}$ kolom, dinotasikan $\mathrm{X}$ seperti berikut:

\subsection{Kemiskinan}

$$
X=\left[\begin{array}{cccc}
X_{11} & X_{12} & \cdots & X_{1 p} \\
X_{21} & X_{22} & \cdots & X_{2 p} \\
\vdots & \vdots & \ddots & \vdots \\
X_{n 1} & X_{n 2} & \cdots & X_{n p}
\end{array}\right]
$$

Kemiskinan adalah suatu kondisi ketidakmampuan secara ekonomi untuk memenuhi standar hidup rata-rata masyarakat di suatu daerah. Masalah kemiskinan merupakan salah satu persoalan mendasar yang menjadi pusat perhatian pemerintah di negara manapun. Pengukuran kemiskinan yang dapat dipercaya dapat menjadi instrumen tangguh bagi pengambil kebijakan dalam memfokuskan perhatian pada kondisi hidup orang miskin. ${ }^{6}$ Data kemiskinan yang baik dapat digunakan untuk mengevaluasi kebijakan pemerintah terhadap kemiskinan, membandingkan kemiskinan antar waktu dan daerah, serta menentukan target penduduk miskin dengan tujuan untuk memperbaiki kondisi mereka.

\subsection{Kaiser-Meyer- Olkin}

Kaiser-Meyer-Olkin digunakan untuk mencari indeks perbandingan jarak antara koefisien korelasi dengan koefisien korelasi parsialnya. ${ }^{7}$ Nilai diatas 0,5 variabel-variabel yang digunakan biasanya juga masih bisa digunakan sebagai penentu dalam analisis faktor namun apabila nilai KMO kurang dari 0,5 variabel-variabel tersebut tidak bisa digunakan untuk analisis faktor atau analisis faktor tidak bisa dilanjutkan.

\subsection{Uji Bartlett's}

Menurut Ifadah Barlett's test digunakan sebagai penguji apakah variabel-variabel yang digunakan benar-benar memiliki korelasi. ${ }^{8}$ Bartlett's Test memiliki hipotesis sebagai berikut:

$\mathrm{H}_{0}$ : didalam variabel bebas tidak ada korelasi.

$\mathrm{H}_{1} \quad$ : didalam variabel bebas terdapat korelasi

Hasil pengujian diketahui dengan melihat hasil nilai signifikasi ( $p$-value) yaitu dengan cara:

Apabila nilai sig. $>0,05 \mathrm{H}_{0}$ diterima dan ditolak $\mathrm{H}_{0}$ jika nilai sig. $<0,05$.

\subsection{Eigen Value}

Eigenvalue adalah kemampuan setiap faktor mewakili variabel yang dianalisis ditujukkan

\footnotetext{
${ }^{6}$ Zuhdiyaty, Noor. 2017. Analisis Faktor - Faktor yang Mempengaruhi Kemiskinan di Indonesia Selama Lima Tahun Terakhir (Studi Kasus Pada 33 Provinsi). JIBEKA. 11(2): 27 - 31.

${ }^{7}$ Mayapada R, Tinungki GM, Sunusi N. 2019. Penerapan Sparse Principal Component Analysis dalam Menghasilkan Matriks Loading yang Sparse. Jurnal Matematika, Statistika \& Komputasi. 15(2): 44-54

${ }^{8}$ Ana Ifadah, Analisis Metode Principal Component Analysis (Komponen Utama) Dan Regresi Ridge Dalam Mengatasi Dampak Multikolinearitas Dalam Analisis Regresi Linear Berganda. Skripsi. Tidak dipublikasikan. 2011. Semarang: Universitas Negeri Semarang.
} 
oleh besarnya varians yang dijelaskan. Eigen value menunjukkan kepentingan relatif masing- masing vektor dalam menghitung varians semua variabel yang dianalisis. Susunan eigen value selalu diurutkan dari yang terbesar sampai yang terkecil, dengan kriteria bahwa eigen value dibawah 1 tidak digunakan dalam menghitung jumlah faktor yang terbentuk. ${ }^{9}$

\section{Metode}

\subsection{Metode Pengumpulan Data}

Data pada penelitian ini berupa data sekunder yang bersumber dari website Badan Pusat Statistik (BPS) dengan kasus data kemiskinan di provinsi Kalimantan tengah pada tahun 2019.

\subsection{Metode Analisis Data}

Metode analisis yang digunakan adalah Principal Component Analysis (PCA). Metode Principal Component Analysis (PCA) merupakan suatu teknik statistik untuk mengubah dari sebagian besar variabel asli yang digunakan yang saling berkorelasi satu dengan yang lainnya menjadi satu set variabel baru yang lebih kecil dan saling bebas. ${ }^{10}$ Principal Component Analysis (PCA) berguna untuk mereduksi data, sehingga lebih mudah untuk menginterpretasikan data -data.

\section{Hasil dan Pembahasan}

Hasil yang diperoleh melalui uji Principal Component Analysis untuk data kemiskinan di Provinsi Kalimantan Tengah pada tahun 2019:

Tabel 4.1 Output KMO dan Bartlett’s Test

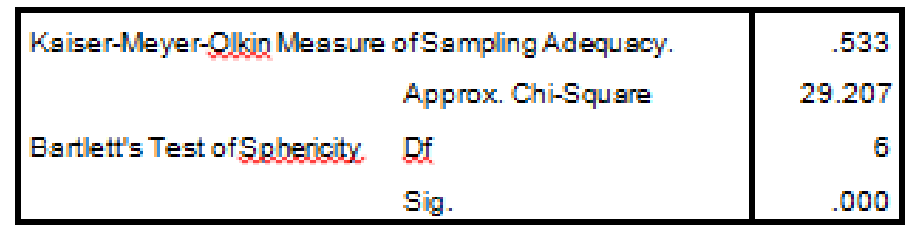

Tabel output KMO and Bartlett's Test untuk mengetahui kelayakan suatu variabel, apakah dapat di proses lebih lanjut menggunakan teknik analisis faktor atau tidak. Jika nilai Kaiser-Meyer-Olkin Measure of Sampling Adequacy (KMO MSA) > 0,50 dan nilai Bartlett's Test of Sphericity (Sig.) < 0,05 maka teknik analisis faktor dapat dilanjutkan.

Berdasarkan output diatas diketahui nilai KMO MSA sebesar 0,533 > 0,050 dan nilai Bartlett's Test of Sphericity (Sig.) 0,000 < 0,05 maka analisis faktor dalam penelitian ini dapat dilanjutkan karena sudah memenuhi persyaratan pertama.

\section{Tabel 4.2 Output Communalities}

${ }^{9}$ Puspitaningrum D, Sari DK, Susilo B. 2014. Dampak Reduksi Sampel Menggunakan Principal Component Analysis (PCA) Pada Pelatihan Jaringan Syaraf Tiruan Terawasi (Studi Kasus: Pengenalan Angka Tulisan Tangan). Jurnal Pseudocode. 2(1): 83 - 89.

${ }^{10}$ Budi A, Inna A, Maulana H. 2016. Pengenalan Citra Wajah Sebagai Identifier Menggunakan Metode Principal Analysis Component Analysis (PCA). Jurnal Teknik Informatika. 9(2): 166 - 175 


\begin{tabular}{|l|r|r|}
\hline & \multicolumn{1}{|c|}{ Initial } & Extraction \\
\hline Dats_Pendidikgo & 1.000 & 1.000 \\
Dats_StatusBekeria & 1.000 & 1.000 \\
Dats_SektorBekeris & 1.000 & 1.000 \\
Data_Pengeluarga_Perkapitg & 1.000 & 1.000 \\
\hline
\end{tabular}

Extraction Method: Principal ComponentAnslysis.

Tabel Communalities ini menunjukkan nilai variabel tersebut mampu menjelaskan faktor atau tidak. Variabel dianggap mampu menjelaskan faktor jika nilai Extraction > 0,50.

Berdasarkan table output diatas, diketahui nilai Extraction untuk semua variabel $1,000>0,50$. Dengan demikian, dapat disimpulkan bahwa semua variabel dapat dipakai untuk menjelaskan faktor.

Gambar 4.1 Scree Plot

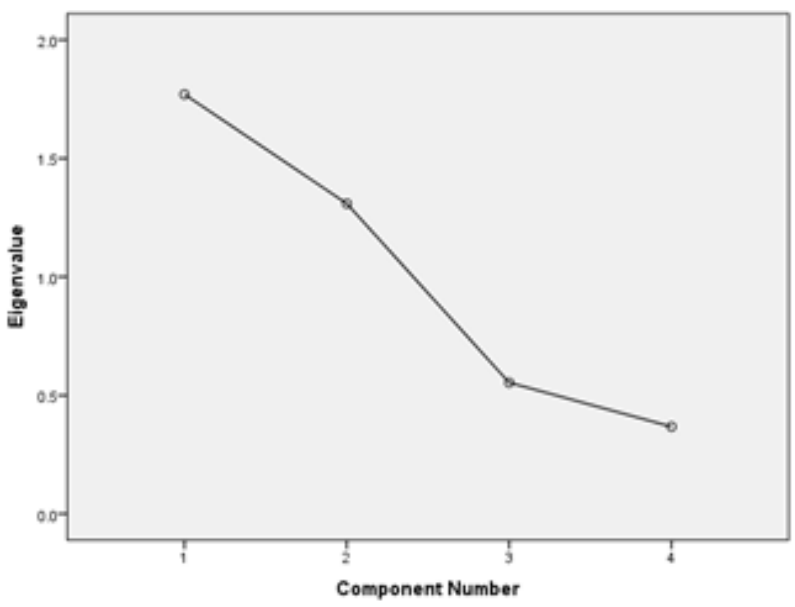

Tujuan dari Scree Plot adalah menunjukkan jumlah faktor yang terbentuk. Caranya dengan melihat nilai titik Component yang memiliki nilai Eigenvalue $>1$. Dari gambar Scree Plot diatas terlihat ada 2 titik Component yang memiliki nilai Eigenvalue $>1$ maka dapat diartikan bahwa ada 2 faktor yang dapat terbentuk.

Tabel 4.3 Output Component Matrix

\begin{tabular}{|c|c|c|}
\hline & \multicolumn{2}{|c|}{ Component } \\
\hline & 1 & 2 \\
\hline Dats Pendidikso & .433 & -.744 \\
\hline Data_StatusBekecia & .888 & .074 \\
\hline Dats_SebtorBekeris & .873 & .118 \\
\hline Dats PengeluaranPerkap its & .179 & .858 \\
\hline
\end{tabular}

Extraction Method: Principal Component/Analysis.

๑. 2 components extracted. 
Component Matrix menunjukkan nilai korelasi atau hubungan antara masing masing variabel dengan faktor yang akan terbentuk. Faktor yang akan terbentuk untuk setiap variable adalah sebagai berikut:

1. Untuk variabel Pendidikan nilai korelasi variabel dengan faktor 1 sebesar 0,433 dan faktor 2 sebesar - 0.744 .

2. Untuk variabel Status Bekerja nilai korelasi variabel dengan faktor 1 sebesar 0.888 dan faktor 2 0,074.

3. Untuk variabel Sektor Bekerja nilai korelasi variabel dengan faktor 1 sebesar 0.873 dan faktor 2 sebesar 0.118 .

4. Untuk variabel Pengeluaran Perkapita nilai korelasi variabel dengan faktor 1 sebesar 0.179 dan faktor 2 sebesar 0.858 .

Tabel 4.4 Output Rotated Component Matrix

\begin{tabular}{|l|r|r|}
\hline \multirow{2}{*}{} & \multicolumn{2}{|c|}{ Component } \\
\cline { 2 - 3 } & 1 & \multicolumn{1}{c|}{2} \\
\hline Dats_Pendidikso & .342 & -.790 \\
Dats_StatusBekeris & .890 & -.032 \\
Dats_SektorBekeris & .881 & .014 \\
Dats_PengelugranPerkapitg & .279 & .831 \\
\hline
\end{tabular}

Extraction Method: Principal ComponentAnslysis.

Rotation Method: Yarimgx with Kaiser Normalization.

a. Rotation converged in 3 iterations.

Untuk memastikan suatu variabel masuk dalam kelompok faktor mana, maka dapat ditentukan dengan melihat nilai korelasi terbesar antara variabel dengan faktor (Component) yang terbentuk.

1. Variabel Pendidikan. Nilai korelasi faktor $1>$ faktor 2 maka variabel pendidikan termasuk kelompok faktor 1.

2. Variabel Status Bekerja. Nilai korelasi variabel dengan faktor $1>$ faktor 2 maka variabel status bekerja termasuk kelompok faktor 1 .

3. Variabel Sektor Bekerja. Nilai korelasi variabel dengan faktor $1>$ faktor 2 maka variabel sektor bekerja termasuk kelompok faktor 1.

4. Variabel Pengeluaran Perkapita. Nilai korelasi variabel dengan faktor $2>$ faktor 1 maka variabel sektor bekerja termasuk kelompok faktor 2 .

Dengan melihat pembahasan di atas maka dapat ditarik kesimpulan adalah sebagai berikut.

Tabel 4.5 Faktor yang terbentuk

\begin{tabular}{|c|l|}
\hline Faktor & \multicolumn{1}{|c|}{ Variabel } \\
\hline 1 & Pendidikan, Status Bekerja, dan Sektor Bekeria \\
\hline 2 & Pengeluaran Perkapitauntuk Makanan \\
\hline
\end{tabular}


Dari tabel diatas dapat diketahui bahwa variabel pendidikan, status bekerja, dan sektor bekerja masuk pada faktor 1, sedangkan variabel pengeluaran perkapita untuk makanan masuk pada faktor 2 .

Tabel 4.6 Output Transformation Matrix

\begin{tabular}{l|r|r|}
\hline Component & \multicolumn{1}{|c|}{1} & \multicolumn{1}{c|}{2} \\
\hline 1 & .993 & -.118 \\
2 & .118 & .993 \\
\hline
\end{tabular}
Extraction Method: Principal
Component Analysis.
Rotation Method: Yarimgx with Kaiser
Normalization.

Component Transformation Matrix menunjukkan bahwa pada component 1 nilai korelasinya adalah sebesar $0,993>0,5$, dan component 2 nilai korelasinya adalah sebesar $0,993>0,5$. Karena nilai korelasi semua component $>0,5$ maka kedua faktor yang terbentuk ini dapat disimpulkan layak untuk merangkum keempat variabel yang dianalisis.

Gambar 4.2 Nilai Eigen

\begin{tabular}{|c|c|c|c|c|c|c|c|}
\hline Eigenvalue & 465.67 & 280.42 & 78.24 & \multicolumn{4}{|c|}{21.29} \\
\hline Proportion & 0.551 & 0.332 & 0.093 & \multicolumn{4}{|c|}{0.025} \\
\hline Cumulative & 0.551 & 0.882 & 0.975 & \multicolumn{4}{|c|}{1.000} \\
\hline \multicolumn{3}{|l|}{ Variable } & & $\mathrm{PCl}$ & $\mathrm{PC} 2$ & $\mathrm{PC} 3$ & $\mathrm{PC} 4$ \\
\hline \multicolumn{3}{|l|}{ Pendidikan } & & 799 & 0.591 & 0.031 & 0.104 \\
\hline \multicolumn{3}{|c|}{ Status Bekerja } & & .446 & -0.555 & -0.699 & -0.064 \\
\hline \multicolumn{3}{|c|}{ Sektor Bekerja } & & .402 & -0.571 & 0.714 & -0.048 \\
\hline Pengeluarar & Perkapi & ta Makan & -0 . & .036 & -0.126 & -0.013 & 0.991 \\
\hline
\end{tabular}

Persamaan PCA 1 adalah sebagai berikut:

$\mathrm{Z}=0,799 \mathrm{X} 1+0,446 \mathrm{X} 2+0,402 \mathrm{X} 3-0,036 \mathrm{X} 4$.. (1)

Persamaan PCA 2 adalah sebagai berikut:

$\mathrm{Z}=0,59 \mathrm{X} 1-0,555 \mathrm{X} 2-0,571 \mathrm{X} 3-0,126 \mathrm{X} 3$.. (2)

Persamaan PCA 3 adalah sebagai berikut:

$\mathrm{Z}=0,031 \mathrm{X} 1-0,699 \mathrm{X} 2+0,714 \mathrm{X} 3-0,013 \mathrm{X} 4$.. (3)

Persamaan PCA 4 adalah sebagai berikut:

$\mathrm{Z}=0,104 \mathrm{X} 1-0,064 \mathrm{X} 2-0,048 \mathrm{X} 3+0,991 \mathrm{X} 4$.. (4)

Dari variabel pendidikan, status bekerja, sektor bekerja, dan pengeluaran perkapita makanan didapatkan eigenvalue sebesar 465.67, 280.42, 78.24, dan 21.29. Variabel pendidikan memiliki eigenvalue terbesar 456.67 yang berarti bahwa variabel pendidikan memiliki pengaruh terbesar dalam kemiskinan di Provinsi Kalimantan Tengah pada tahun 2019. 


\section{Kesimpulan}

Kesimpulan yang didapat dari analisis yang telah dilakukan adalah sebagai berikut:

1. Principal Component Analysis dapat digunakan untuk membentuk variabel baru dengan mengurangi dimensi dari variabel pembentuknya.

2. Pada output scree plot didapatkan jumlah faktor yang terbentuk sebanyak 2 faktor. Variabel pendidikan, status bekerja, dan sektor bekerja termasuk kedalam faktor 1, sedangkan untuk variabel pendapatan perkapita untuk makanan termasuk kedalam faktor 2.

3. Variabel pendidikan memiliki eigenvalue terbesar 456.67 yang berarti bahwa variabel pendidikan memiliki pengaruh terbesar dalam kemiskinan di Provinsi Kalimantan Tengah pada tahun 2019. Berarti kebijakan pemerintah dalam menanggulangi kemiskinan adalah dengan meningkatkan pembangunan pada bidang pendidikan.

\section{Daftar Pustaka}

Badan Pusat Statistik. 2019. Data dan Informasi Kemiskinan Kabupaten/Kota. Diakses dari https://www.bps.go.id/publication/2019/12/10/665478edc012d93f7961518f/data-daninformasi-kemiskinan-kabupaten--kota-tahun-2019.html pada tanggal 10 Desember 2019, pukul 20.12 WITA.

Budi A, Inna A, Maulana H. 2016. Pengenalan Citra Wajah Sebagai Identifier Menggunakan Metode Principal Analysis Component Analysis (PCA). Jurnal Teknik Informatika. 9(2): $166-175$.

Ifadah, Ana. 2011. Analisis Metode Principal Component Analysis (Komponen Utama) Dan Regresi Ridge Dalam Mengatasi Dampak Multikolinearitas Dalam Analisis Regresi Linear Berganda. Skripsi. Tidak dipublikasikan. Semarang: Universitas Negeri Semarang

Mayapada R, Tinungki GM, Sunusi N. 2019. Penerapan Sparse Principal Component Analysis dalam Menghasilkan Matriks Loading yang Sparse. Jurnal Matematika, Statistika \& Komputasi. 15(2): 44 - 54.

Puspitaningrum D, Sari DK, Susilo B. 2014. Dampak Reduksi Sampel Menggunakan Principal Component Analysis (PCA) Pada Pelatihan Jaringan Syaraf Tiruan Terawasi (Studi Kasus: Pengenalan Angka Tulisan Tangan). Jurnal Pseudocode. 2(1): 83 - 89.

Rustam, Mochtar. 2010. Sinopsis Obstetri Fisiologi Patologi 3rd ed. Jakarta: EGC.

Zuhdiyaty, Noor. 2017. Analisis Faktor - Faktor yang Mempengaruhi Kemiskinan di Indonesia Selama Lima Tahun Terakhir (Studi Kasus Pada 33 Provinsi). JIBEKA. 11(2): 27 - 31. 